\title{
Retrospective review of cystic fibrosis presenting as infantile liver disease
}

\author{
Riki Shapira, Nedim Hadžić, Ruggiero Francavilla, George Koukulis, John F Price, \\ Giorgina Mieli-Vergani
}

\begin{abstract}
The mode of presentation, clinical course, and outcome of 12 infants with cystic fibrosis and liver disease referred over an 18 year period were investigated retrospectively. Median age at presentation was 6.5 weeks (range, 5-12). Two thirds were boys. Conjugated hyperbilirubinaemia was the presenting symptom in 11 patients, and hypoalbuminaemia in one. Jaundice was cleared over a median period of 7.36 months. Eight patients had bile duct proliferation on liver biopsy and one required cholangiography to exclude biliary atresia. Classic histological features of cystic fibrosis were only present in two children biopsied at 8 and 18 months. Three patients had meconium ileus, including one infant with concomitant $\alpha_{1}$ antitrypsin deficiency, who required early liver transplantation. All other patients had no signs of significant chronic liver disease during a median follow up of 42 months (range, 10-205). Children with cystic fibrosis and infantile liver disease have a good short and medium term prognosis.
\end{abstract}

(Arch Dis Child 1999;81:125-128)

Keywords: cystic fibrosis; conjugated

hyperbilirubinaemia; chronic liver disease

Cystic fibrosis (CF) is an autosomal recessive disorder of ion transport inducing clinical disease in a variety of organs including lungs, exocrine pancreas, liver, and gut. ${ }^{1}$ There are more than 600 mutations described in the CF transmembrane regulator (CFTR) gene, located on the long arm of chromosome 7 (7q31), which result in failure of the cAMP chloride channel transport mechanism. ${ }^{12}$ CFTR is a glycoprotein located at the apical region of epithelial cells in different organs including airways, intestine, pancreatic ducts, and bile ducts. ${ }^{3}$

Pronounced liver disease on the basis of clinical, biochemical, and ultrasonographic criteria develops in about $20 \%$ of patients with $\mathrm{CF}^{4}$ Risk factors are pancreatic insufficiency, ${ }^{1}$ possession of human leucocyte antigen (HLA) type DQ6, ${ }^{5}$ male sex ${ }^{6}$ and presentation with meconium ileus or its equivalent. ${ }^{78}$ Different CFTR mutations appear not to play a role in the development of liver disease.

A rare form of liver involvement in $\mathrm{CF}$ is hepatitis of infancy. In the only published series, an overall prevalence of $0.61 \%$ and a mortality rate of $55 \%$, caused by cardiorespira- tory and liver failure, was reported in a cohort of nine infants. ${ }^{10}$

To investigate the incidence, clinical and histological features, and outcome of CF related infantile liver disease in our centre we analysed retrospectively all children with this condition referred over a period of 18 years.

\section{Patients and methods}

Our unit is a tertiary referral centre to which about 100 neonates and young infants with conjugated hyperbilirubinaemia are referred each year. Between 1980 and 1997, 12 infants with liver function test abnormalities were diagnosed to have CF on the basis of abnormal sweat tests. Molecular genetics screening for the most common mutations in the UK population, including $\Delta \mathrm{F} 508, \mathrm{G} 542 \mathrm{X}, \mathrm{G} 551 \mathrm{D}$, and $621+1 \mathrm{G}>\mathrm{T}$, was performed in 10 patients (CF(4)m PCR; Kodak Clinical Diagnostics, Amersham, UK). Other causes of conjugated hyperbilirubinaemia in infancy were excluded by appropriate investigations. Eleven needle biopsies from 10 patients were available. Histological evaluation was performed by a single histopathologist (GK), who assessed the following variables: cholestasis, expansion of portal tracts, ductular proliferation, cholangiolitis, fibrosis, giant cell transformation, steatosis, iron deposition, and haemopoiesis. ${ }^{11}$ The changes were described as focal when present in a small subset of portal tracts and prominent when seen in a large proportion of liver parenchyma.

\section{Results}

Table 1 gives the clinical features of the 12 children at presentation and follow up. Eleven patients were white and one Asian (patient 2). Eleven presented with conjugated jaundice, one with severe hypoalbuminaemia (patient 3 ). All pregnancies were normal and all but one child (patient 2) were born at term. There was no previous family history of CF. Eight patients were boys. Median age at presentation was 6.5 weeks (range, 5-12 weeks). Median birth weight was $3270 \mathrm{~g}$ (range, 1900-4600). Eight patients had chest symptoms at presentation ranging from cough to pneumonia. One patient (patient 12) was found also to have $\alpha_{1}$ antitrypsin deficiency (PiZZ phenotype). Hepatomegaly was present in 10 and splenomegaly in three children. There were no gross ultrasonographic abnormalities at presentation, but patient 2 had inspissated bile in the gallbladder. Three patients had meconium ileus, including the patient with $\alpha_{1}$ antitrypsin deficiency. Genetic analysis demonstrated 
Table 1 Clinical features of patients at presentation and follow up

\begin{tabular}{|c|c|c|c|c|c|c|c|c|c|c|c|c|c|c|c|c|}
\hline \multirow[b]{2}{*}{ Case } & \multirow[b]{2}{*}{ Sex } & \multirow{2}{*}{$\begin{array}{l}\text { Age } \\
\text { (weeks) }\end{array}$} & \multirow[b]{2}{*}{ CF mutation } & \multicolumn{7}{|c|}{ Presentation } & \multirow{2}{*}{$\begin{array}{l}\text { Follow up } \\
\text { (months) }\end{array}$} & \multicolumn{4}{|c|}{ Follow up } & \multirow{2}{*}{$\begin{array}{l}\text { Clinical } \\
\text { condition/remarks }\end{array}$} \\
\hline & & & & $M I$ & $f$ & $H A$ & $H$ & $S$ & $C S$ & $F T T$ & & $C L D$ & $F T T$ & $H$ & $S$ & \\
\hline 1 & M & 5 & NI & - & $\mathrm{Y}$ & - & ++ & + & $\mathrm{Y}$ & - & 12 & - & - & ++ & ++ & Well \\
\hline 2 & $\mathrm{M}$ & 6 & $\Delta \mathrm{F} 508 / \Delta \mathrm{F} 508$ & - & $\mathrm{Y}$ & - & ++ & - & - & - & 27 & ++ & - & + & - & Well \\
\hline 3 & M & 12 & $\Delta \mathrm{F} 508 / \mathrm{NI}$ & - & - & $\mathrm{Y}$ & - & - & $\mathrm{Y}$ & $\mathrm{Y}$ & 24 & + & - & - & - & Well \\
\hline 4 & $\mathrm{~F}$ & 6 & $\Delta \mathrm{F} 508 / \Delta \mathrm{F} 508$ & $\mathrm{Y}$ & $\mathrm{Y}$ & - & ++ & + & - & - & 13 & + & - & ++ & + & Well \\
\hline 5 & $\mathrm{M}$ & 6 & $\Delta \mathrm{F} 508 / \mathrm{NI}$ & - & $\mathrm{Y}$ & - & + & - & $\mathrm{Y}$ & $\mathrm{Y}$ & 184 & + & + & + & - & Delayed puberty \\
\hline 6 & $\mathrm{M}$ & 8 & $\Delta \mathrm{F} 508 / \Delta \mathrm{F} 508$ & - & $\mathrm{Y}$ & - & - & - & - & - & 205 & - & - & - & - & Well \\
\hline 7 & M & 5 & $\Delta \mathrm{F} 508 / \mathrm{G} 542 \mathrm{X}$ & - & $\mathrm{Y}$ & - & + & - & $\mathrm{Y}$ & $\mathrm{Y}$ & 155 & +++ & - & + & - & $\begin{array}{l}\text { Glucose } \\
\text { intolerance }\end{array}$ \\
\hline 8 & $\mathrm{~F}$ & 7 & $\Delta \mathrm{F} 508 / \Delta \mathrm{F} 508$ & $\mathrm{Y}$ & $\mathrm{Y}$ & - & +++ & - & $\mathrm{Y}$ & - & 178 & ++ & - & + & - & Well \\
\hline 9 & $\mathrm{~F}$ & 8 & Not tested & - & $\mathrm{Y}$ & - & +++ & - & $\mathrm{Y}$ & - & 106 & ++ & - & - & - & Well \\
\hline 10 & $\mathrm{M}$ & 8 & $\Delta \mathrm{F} 508 / \Delta \mathrm{F} 508$ & - & $\mathrm{Y}$ & - & + & - & - & $\mathrm{Y}$ & 37 & + & - & + & - & MRSA positive \\
\hline 11 & $\mathrm{~F}$ & 5 & $\Delta \mathrm{F} 508 / \Delta \mathrm{F} 508$ & - & $\mathrm{Y}$ & - & + & - & $\mathrm{Y}$ & $\mathrm{Y}$ & 47 & + & - & - & - & Well \\
\hline $12 \dagger$ & M & 7 & $\Delta \mathrm{F} 508 / \Delta \mathrm{F} 508$ & $\mathrm{Y}$ & $\mathrm{Y}$ & - & ++ & + & $\mathrm{Y}$ & - & 10 & +++ & - & ++ & ++ & $\alpha_{1} \mathrm{ATD} / \mathrm{OLT}$ \\
\hline
\end{tabular}

*At presentation.

$\dagger$ Patient excluded from follow up analysis after orthotopic liver transplantation (OLT)

NI, not identified; MI, meconium ileus; J, jaundice; HA, hypoalbuminaemia; H, hepatomegaly; S, splenomegaly; CS, chest symptoms; FTT, failure to thrive; CLD, chronic lung disease; MRSA, methicillin resistant Staphylococcus aureus; $\alpha_{1}$ ATD, $\alpha_{1}$ antitrypsin deficiency.

Y, present; -, absent; +, mild; ++, moderate; +++, severe.

homozygosity for $\Delta \mathrm{F} 508$ in seven of 11 patients tested $(63.6 \%)$. In one patient, who had features of large bile duct obstruction on liver biopsy and acholic stools, biliary atresia had to be excluded by endoscopic retrograde cholangiopancreatography. All children received regular long term fat soluble vitamin supplements, and seven patients, diagnosed after 1988, received ursodeoxycholic acid (UDCA; $15-20 \mathrm{mg} / \mathrm{kg} /$ day). All patients cleared their jaundice over a median period of 7.36 months (range, 3.3-12.0). Median follow up is 42 months (range, 10-205) from presentation (table 1). The patient with concomitant $\alpha_{1}$ antitrypsin deficiency required liver transplantation at 10 months of age and his explanted liver showed advanced micronodular cirrhosis with abundant periodic acid Schiff positive granules. He was excluded from further follow up analysis. At last follow up, seven of 11 patients had mild hepatomegaly, with livers palpable for 1-4 cm below the costal margin. Two patients had spleens palpable to $1 \mathrm{~cm}$ and $4 \mathrm{~cm}$ below the costal margin, respectively. Biochemical tests of liver function (bilirubin, aspartate aminotransferase, $\gamma$-glutamyl transpeptidase, albumin, and prothrombin time) were normal in all but one patient, who had a marginally raised $\gamma$-glutamyl transpeptidase $(\gamma \mathrm{GT})$ of $61 \mathrm{IU} /$ litre (table 2$)$. Follow up ultrasound scans were available in seven patients, demonstrating finely heterogeneous liver in one patient and increased reflectivity within the liver parenchyma in two other children, one of whom had also developed polyps in the gall bladder during a 15 year follow up. The remaining four ultrasound scans were normal.

Table 2 Biochemical parameters at time of presentation and at most recent follow up

\begin{tabular}{lccl}
\hline & $\begin{array}{l}\text { Median serum } \\
\text { concentrations at } \\
\text { presentation (range) }\end{array}$ & $\begin{array}{l}\text { Median serum } \\
\text { concentrations at } \\
\text { follow up (range) }\end{array}$ & Normal values \\
\hline Bilirubin & $127.5(16-180)$ & $4(2-8)$ & $<20 \mu \mathrm{mol} / 1$ \\
AST & $183(110-402)$ & $29(22-43)$ & $<50 \mathrm{IU} / 1$ \\
$\gamma$ GT & $336(91-1263)$ & $19(6-61)$ & $<55 \mathrm{IU} / 1$ \\
Alkaline phosphatase & $365(184-885)$ & $234(87-330)$ & $<350 \mathrm{IU} / 1$ \\
Albumin & $37.5(21-46)$ & $43(38-50)$ & $35-50 \mathrm{~g} / 1$ \\
INR & $1.01(0.8-1.8)$ & $0.95(0.8-1.0)$ & $0.8-1.2$ \\
\hline
\end{tabular}

AST, aspartate aminotransferase ; $\gamma \mathrm{GT}$, gamma-glutamyl transpeptidase; INR, international normalised ratio.
During follow up, one patient failed to thrive and four others developed moderate to severe lung disease. Of the remaining patients, one had delayed puberty, one glucose intolerance, and one respiratory tract colonisation with methicillin resistant Staphylococcus aureus.

\section{HISTOLOGICAL FEATURES}

Liver histology was available in 10 infants, with a median age at biopsy of 5.2 months (range, 1.5-18.6). One patient, who eventually required cholangiography to rule out biliary atresia, had two biopsies. Table 3 shows the histological findings. At least six portal spaces were present in each specimen. Expansion of portal tracts, either diffuse (eight biopsies) or focal (three biopsies), was the constant feature observed. Four of these patients had bridging fibrosis. Ductular proliferation was demonstrated in eight livers, and giant cell transformation in five. Diffuse fatty change was seen in one, whereas less prominent periportal fatty infiltration was seen in four biopsies. Focal extramedullary haemopoiesis was present in six and islets of spotty necrosis in four children. Only two patients, in whom the biopsy was performed at 8 and 18 months of age, had the focal deposits of pink/orange material in dilated ductules characteristically seen in older patients with $\mathrm{CF}$ and liver disease. Median age at biopsy of the remainder of the group was 4.2 months (range, 1.2-11.1).

Table 3 Histological features at presentation

\begin{tabular}{lllr}
\hline & \multicolumn{2}{c}{ Number of biopsies } \\
\cline { 2 - 4 } & $\begin{array}{l}\text { Diffuse or } \\
\text { prominent }\end{array}$ & $\begin{array}{l}\text { Focal or not } \\
\text { prominent }\end{array}$ & Total \\
Histopathological feature & 8 & 3 & 11 \\
\hline $\begin{array}{l}\text { Portal expansion and fibrosis } \\
\text { Ductular proliferation/ }\end{array}$ & 6 & 2 & 8 \\
$\quad$ cholangiolitis & & & \\
$\begin{array}{l}\text { Pink/orange material in dilated } \\
\quad \text { ductules }\end{array}$ & 0 & 2 & 2 \\
$\begin{array}{l}\text { Giant cell transformation } \\
\text { Steatosis }\end{array}$ & 3 & 2 & 5 \\
Lobular fibrosis & 1 & 4 & 5 \\
Spotty necrosis & 0 & 1 & 1 \\
Kupffer cell activation & 0 & 4 & 4 \\
Haemopoesis & 10 & 0 & 10 \\
Iron granules in periportal & 1 & 6 & 7 \\
$\quad$ hepatocytes & 5 & 2 & 7 \\
\hline
\end{tabular}




\section{Discussion}

Our data suggest that CF related neonatal liver disease has a good short and medium term prognosis, with few patients progressing to overt chronic liver disease. The only child in our series requiring a liver transplant was a boy who also had $\alpha_{1}$ antitrypsin deficiency, with explanted liver histological appearance more likely to be related to this condition than CF. Only two of the remaining 11 patients had appreciable hepatosplenomegaly and only one had minimally abnormal liver function tests. These results agree with those of an early study from our unit, ${ }^{12}$ but contrast with those of the recently published French series, ${ }^{10}$ where five of nine children died, four before their 5 th birthday and one at 19 years of age. Although three of them died of cardiopulmonary complications, one died of liver failure at 5 months and one, who died at 6 months of meningitis, was cirrhotic at necropsy. This difference in outcome might be because of the small number of patients in both series, with a chance clustering of more severe cases in one. Although genetic analysis was performed in only one of the French patients, it is unlikely that the discrepancy in outcome is the result of different genetic mutations, because there is no reason to believe that genetic markers should differ in the two series.

Seven of our infants were treated early with UDCA, after reports of its beneficial effect in improving biochemical and clinical features in late onset $\mathrm{CF}$ related liver disease. ${ }^{13}$ It is speculative whether UDCA treatment is the reason for the better liver prognosis in our patients compared with the French cohort, of whom only two received this drug.

The most common presentation of $\mathrm{CF}$ related liver disease in infancy is conjugated hyperbilirubinaemia, present in 11 of 12 children in our series and in all patients in the French study. The overall incidence of CF as a cause of neonatal cholestasis is similar in our study $(0.7 \%)$ and the French study $(0.62 \%)$. Our analysis suggests that infants with CF require a much longer period to clear their jaundice (median, 7.36 months) than those with other medical disorders presenting with neonatal jaundice (median, 2.5) ${ }^{14}$ Both series contained a patient with CF and $\alpha_{1}$ antitrypsin deficiency. Therefore, the presence of one condition leading to infantile liver disease should not preclude further investigations for other causes. Cystic fibrosis must be excluded in all infants with prolonged conjugated jaundice, particularly if they are white.

We observed a preponderance of boys in our study, akin to that reported for CF related liver disease of childhood, ${ }^{67}{ }^{15}$ but this was not the case in the French series, where five of the nine infants were girls.

An abnormal sweat test, malabsorption, and failure to thrive can also be present in patients with progressive familial intrahepatic cholestasis, but usually family history, progressive jaundice, distinctive biochemical markers, and the presence of pruritus allow the differential diagnosis. In difficult cases molecular genetic stud- ies, which are available for both conditions, should be performed. ${ }^{9} 16$

Most of our patients had portal expansion with biliary features on liver biopsy. In one patient, with florid biliary features indistinguishable from biliary atresia, cholangiography was required to document patency of the extrahepatic bile ducts. The histological hallmark of CF related liver disease in older patients is the deposition of an amorphous, pink to light orange material in dilated cholangioles. ${ }^{17}$ This feature was present in only two infants, who were biopsied at 8 and 18 months of age, much later than the median age at biopsy of the remaining 10 patients (4.2 months), suggesting that it develops over time. Steatosis, reported as a common feature in $\mathrm{CF},{ }^{11}$ was severe in only one patient. Mild, predominantly periportal, steatosis was seen in approximately one third of the biopsies.

The children described in this series have an excellent short and medium term hepatic prognosis, although two of them had pronounced hepatosplenomegaly at the latest review. Whether their prognosis will remain good can only be established by a much longer follow up. Clinically important late onset CF related chronic liver disease, usually presenting during adolescence, is not associated with a history of neonatal jaundice, but of meconium ileus. ${ }^{78}$ Of the three children presenting with meconium ileus in our series, one has required a liver transplant for associated $\alpha_{1}$ antitrypsin deficiency, one has only minimally raised $\gamma$ glutamyl transpeptidase, but already moderate hepatosplenomegaly 13 months after diagnosis, whereas the third has mild hepatomegaly and normal liver function tests at last follow up 178 months from presentation. Infants with CF presenting with meconium ileus, requiring surgical management and prolonged total parenteral nutrition, might have a different prognosis from our group. The infants described in our paper represent a selected group of patients with CF, referred to a paediatric hepatology centre because of neonatal liver disease. The real incidence of CF related liver involvement in infancy might be higher if the analysis included infants presenting to neonatal units with meconium ileus, requiring surgical management and prolonged total parenteral nutrition.

We conclude that $\mathrm{CF}$ is a rare cause of infantile cholestasis with a good medium term prognosis. Whether CF related neonatal liver disease leads to the more frequent CF related chronic liver disease of childhood and adolescence will need to be established in larger series with longer follow up.

1 Shalon LB, Adelson JW. Cystic fibrosis: gastrointestinal complications and gene therapy. Pediatr Clin North Am 1996;43:157-96.

2 Rosenstein BJ, Zeitlin PL. Cystic fibrosis. Lancet 1998;351: 277-82.

3 Tanner MS, Taylor CJ. Liver disease in cystic fibrosis. Arch Dis Child 1995;72:281-4.

4 Colombo C. Battezzati PM, Podda M. Hepatobiliary disease in cystic fibrosis. Semin Liver Dis 1994;14:25969.

5 Duthie A, Doherty DG, Donaldson PT, et al. The major histocompatibility complex influences the development of 
chronic liver disease in male children and young adults with cystic fibrosis. F Hepatol 1995;25:532-7.

6 Scott-Jupp R, Lama M, Tanner MS. Prevalence of liver disease in cystic fibrosis. Arch Dis Child 1991;66:698-701.

7 Colombo C, Apostolo MG, Ferrari M, et al. Analysis of risk factors for the development of liver disease associated with cystic fibrosis. F Pediatr 1994;124:393-9.

8 Maurage C, Lenaerts C, Weber A, Brochu P, Yousef I, Roy CC. Meconium ileus and its equivalent as a risk factor for the development of cirrhosis: an autopsy study in cystic fibrosis. F Pediatr Gastroenterol Nutr 1989;9:17-20.

9 Duthie A, Doherty DG, Williams C, et al. Genotype analysis for delta F508, G551D and R553X mutations in children and young adults with cystic fibrosis with and without chronic liver disease. Hepatology 1992;15:660-4.

10 Lykavieris P, Bernard O, Hadchouel M. Neonatal cholestasis as the presenting feature in cystic fibrosis. Arch Dis Child 1996;75:67-70.

11 Oppenheimer EH, Esterly JR. Pathology of cystic fibrosis: review of the literature and comparison with 146 autopsied cases. In: Rosenberg HS, Rolande RP, eds. Perspectives in pediatric pathology. St. Louis: Year Book Medical Publishers, 1975:241-78.
12 Psacharopoulos HT, Howard ER, Portmann B, Mowat AP, Williams R. Hepatic complications of cystic fibrosis. Lancet 1981;ii: $78-80$.

13 Colombo C, Battezzati PM, Podda M, Bettinardi N, Giunta A. Ursodeoxycholic acid for liver disease associated with cystic fibrosis: a double-blind multicenter trial. The Italian group for the study of ursodeoxycholic acid in cystic fibrosis. Hepatology 1996;23:1484-90.

14 Dick MC, Mowat AP. Hepatitis syndrome of infancy-an epidemiological survey with 10 -year follow up. Arch Dis Child 1985;60:512-16.

15 Feigelson J, Anagnostopoulos C, Poquet M, Pecau Y, Munck A, Navarro J. Liver cirrhosis in cystic fibrosistherapeutic implications and long term follow up. Arch Dis Child 1993;68:653-7.

16 Bull LN, Carlton VE, Stricker NL, et al. Genetic and morphological findings in progressive familial intrahepatic cholestasis (Byler disease [PFIC-1] and Byler syndrome): evidence for heterogeneity. Hepatology 1997;26:155-64.

17 MacSween RNM, Anthony PP, Scheuer PJ, Burt AD, Portmann BC. Pathology of the liver, 3rd ed. Edinburgh: Churchill Livingstone, 1994:192-6. 